\title{
AMELOGÊNESE IMPERFEITA: UM RELATO DE CASO
}

Josi Karla AMADEU; Cilmara Aparecida VIECHNIESKI; Marcela Lima Cardoso SELOW; Iran VIEIRA

Dentre as diversas patologias relacionadas ao esmalte dentário está a Amelogênese Imperfeita, um defeito hereditário autossômico dominante, recessivo ou ligado ao X. Os defeitos genéticos afetam principalmente o funcionamento de proteínas, como a amelogenina. Clinicamente, apresenta-se mole e destacável ou duro e defeituoso. Neste trabalho foi feita uma revisão de literatura apresentando a etiologia, os subtipos, as características clínicas, histológicas e radiográficas da Al. Também será apresentado o caso de um paciente atendido na Clínica de Semiologia Aplicada do Curso de Odontologia da UFPR. 